\title{
Architecture: Problems of Translation
}

\author{
Dr. Livio Dimitriu \\ Pratt Institute School of Architecture, 200 Willoughby Avenue \\ Brooklyn, NY 11205, USA \\ usainst@gmail.com
}

\begin{abstract}
For the past few centuries, architecture has been systematically discussed in Western culture as a "language", autonomous from other disciplines and yet influenced by them. Architects study the complexity of culture that surrounds them and attempt to make their work a mirror of it: geometry, biology, all of the arts, philosophy, sociology, etc. The predicament in transforming such an enormous variety of interests in a built form that is to be inhabited involves a process of translation from one "language" into another. For example, geometry is not architecture, yet architecture employs it; poetry is not architecture, yet architecture makes use of it. The paper examines a few case studies concerned with the methodology of translation among poetry, painting, sound, sculpture and architecture: Rimbaud, Apollinaire, and Juan Gris, and Livio Dimitriu's Stairwells volume (1974-1979) inside the New York avant-garde movement Pamphlet Architecture; the sculptor's Constantin Brancusi's Targu Jiu Complex in Romania (1936-1937); Le Corbusier's Maison Cook in Paris (1927). What makes for an act of translation to fail? What makes for an act of translation to succeed? It involves moving from one discipline to another, and similarly from one language to another. Where literalness does stop, and where does "creative intuition" take over? The conclusion involves the extraordinary impact of Marcel Duchamp inside Twentieth Century, as best exemplified in architecture by the most original oeuvre of the Carlo Scarpa.
\end{abstract}

\section{Architecture: Autonomous Language}

Since the Italian Renaissance, Western culture has systematically discussed architecture as a "language" autonomous from other disciplines, yet influenced by, and incorporating them. Architects study the complexity of surrounding culture and attempt to make their work a mirror of it: geometry, biology, all of the arts, philosophy, sociology, etc. The linguistic analogy as applied to architecture is here to stay whether one may agree with it or not.

The notion of the autonomy of architecture became fundamental to Italian theory and criticism, and practice, through the 1970s and is still going strong today, with world-wide impact.

The view of architecture as a language and autonomous in nature is fundamental to this discussion. In layman's terms, autonomy signifies in this context that archi- tecture can operate independently of other disciplines, similarly to how English can operate independently of other languages, let's randomly say Romanian or Mongolian, even though it may react to the nature of and developments in such other languages.

The predicament of architecture consists in transforming its enormous variety of interests into a built form that is to be inhabitable. The process involves a translation from the "languages" of various other fields of endeavor into the specific language of architecture. For example, geometry is not architecture, yet architecture employs it; poetry is not architecture, yet architecture makes use of it. The problems of translation from another discipline into architecture are identical to those encountered in literature, for example. Literal translation is possible 
and required in the case of exact sciences, but becomes totally ineffective when it comes to poetry. A common error in architecture and espe-cially in the teaching of architecture is to require correct linear thinking. No doubt, linear thinking ought to be taught. But impeccable linear thinking cannot be con- fused with the creative act that necessitates knowing when and how to deviate from and especially break the rules once the rules are under control. In this sense, a creative break-through in physics, for instance, has always involved both rules and breaking the rules.

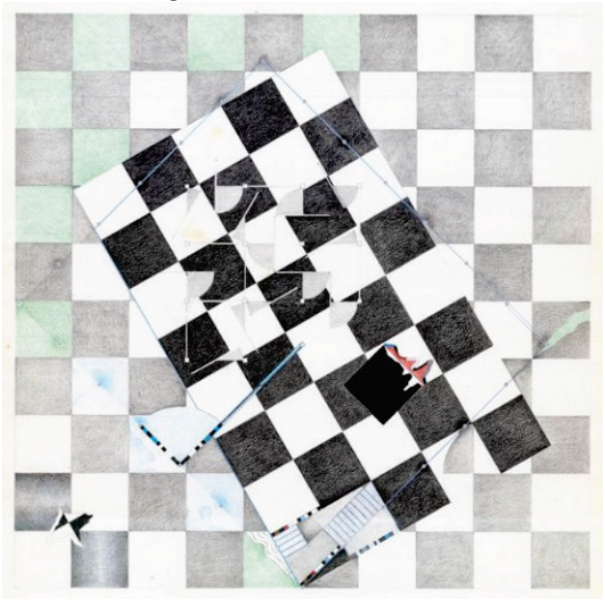

Figure 1. RAG (Rimbaud - Apollinaire - Gris) House, unpublished plan study, 1975-1976.

\section{To Inhabit a Poem}

The examples offered in this analysis deal first with the impossibility of trans-lating literally from other disciplines, even related ones such as painting, poetry, and music, into architecture. The project for the RAG (Rimbaud - Apollinaire - Juan Gris) House, 1975-1976 (Figure 1), while perhaps visually compelling to some, is but an early and literal attempt on my part to make a poem / a painting habitable, architecturally speaking. Rimbaud's synesthesia proposed in the poem Délires / Alchimie $d u$ verbe / Voyelles (1873) provided the color-coding of sound and was applied to Apollinaire's poem The Three Musicians in Calligrammes (1918).
The printed shape, the image of this poem, is homage to Picasso's painting by the same name from the Analytical Cubism period. The compositional method that wraps up the expression of the architecture project is also a Cubist one derived from studying the painting of Juan Gris of the same period.

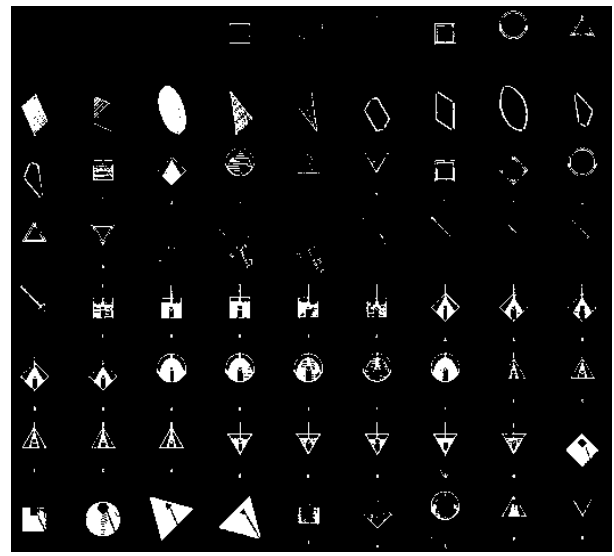

Figure 2. Livio Dimitriu, Stairwells synoptic panel, 1974-1979.

Despite the apparent visual complexity of the imagery, the resulting project cannot escape the linearity of its thinking, the literalness of the translation in this case, the fear of breaking rules once they have been established and digested. This early project fails in producing the invention of a surprising space, the ultimate goal of all architecture.

What is lacking? I had quasi-intuitively understood, as early as 1974, that there was a need for a personal vocabulary, the rudiments of language for space-making and its rules of transformation. By 1978, I developed a personal, private "language" with syntax and grammar that permitted over the following decade an explosion of nationally and internationally award winning projects. The fundamental study Stairwells was started in 1974, and published in 1980 (Figure 2), among the first issues of the avant-garde Pamphlet Architecture Series which I co-founded. It was re-published by Princeton University Press [1,2]. Dr. Alberto Sartoris, one of the few surviving 
members of the original founding group of the Modern Movement at the Congress of La Sarraz (Switzerland) hailed Stairwells in very complimentary terms when the study was republished in 1988 . The rules of permutations and combination possible by the elements of Stairwells are not unlike the use and re-use of words when writing poetry, a process in which breaking syntax in a controlled context produces a sense of wonder and bewilderment essential to all artistic endeavors, and I would venture to say essential to all scientific breakthroughs as well, such as the shift from Newton to Einstein's physics, and beyond.

\section{Brancusi at Targu Jiu: Methodology}

In the case of Stairwells one speaks of "form polluted by function". "Polluted" is employed here with a positive and constructive connotation: form that is transformed by function. An alternative lesson can be learned from sculptor Constantin Brancusi's Targu Jiu Complex (1937). My analysis of Targu Jiu Complex was first published in 1974 (Figure 3) and was widely accepted after a lengthy series of lectures in the US and abroad on the subject of Brancusi Architect. The position was hailed in 1988 , by the most important historian of architecture alive today, Prof. Kenneth Frampton of Columbia University, as one of the few fresh perspectives on Brancusi, in memory. The argument for analysis is based on documentation provided in footnotes, in Barbu Brezianu's primary source volume Brancusi in Romania (1972).These Brancusi sculptures for public spaces, function has been systematically removed. The Gate of the Kiss was originally intended to be the actual gate of the Municipal Park. Brancusi insisted to shift the gate to the inside of the park. There is no evidence why he did so. The image of "gate" for this sculpture becomes stronger precisely because its function has been weakened as much as possible. Brancusi employed the same strategy by when it came to The Table of Silence. Its layout went through three stages, the last one being the final (Figure 3 ). In this case also there is no evidence as to why he did so, except that the sequence of changes reveals clearly the reason. In the first stage, paired chairs were placed close to the table.

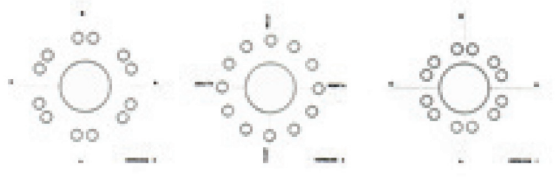

Figure 3. Analysis of successive versions considered by Brancusi for the layout of the Table of Silence, Targu Jiu, Romania, 1936-1937.

The distance from the chairs to the table and among the chairs was a functional one. The resulting image is one that involves 12 people potentially engaged in a noisy conversation while having a meal. The second stage preserved the paired chairs but increase the distance to the table. The mental image becomes that the intimacy of couples interacting around the table, with the table impossible to use. This becomes the equivalent of a gathering of people speaking in sotto voce. The final version involves twelve chairs placed away from the table and evenly spaced away one from another. The specificity of the dimensions involved erodes functional connotations such as eating at this table or conversations among visitors seated around it. Once the function has been eliminated, silence can reign undisturbed, and thus: The Table of Silence. Brancusi's sculptures are achieved by the elimination of function.

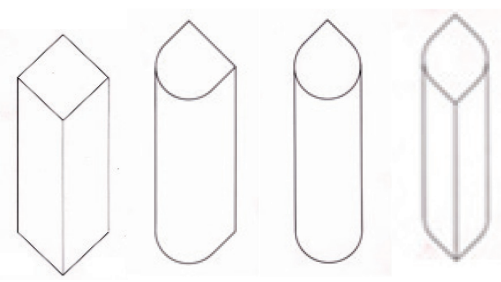

Figure 4. Transformations of the central column, from ground to the roof levels, in Le Corbusier's Maison Cook, Paris, France, 1927. 


\section{Le Cobusier's Methodology}

In Maison Cook in Paris (1927), Le Corbusier sets up a very complex system of reading though the placement and shape of structural columns. The vertical column at the center of the plan, attached to the main stair of the house, constantly changes shape as it moved vertically from one floor to another (Figure 4). The shape at each individual floor gives the visitor a clue as to the nature of the movement on that particular floor. The stacking of the column's various shapes, the assemblage of forms, can only be achieved as a mental exercise. It is not possible to see it with the eye, but it can be seen with the eye of the mind. Le Corbusier achieves architecture by allowing form to be imbued with function. Yet the mental image of the entire column piercing the section of the building speaks of rotation in space and is not concerned with the specificity of functional solutions at each floor. This mental image is evidently indebted in its meaning to Brancusi's series of Birds in Space, vertical columns assembling various shapes for bases, the connection between base(s) and the bird, and the bird itself.

\section{Marcel Duchamp's Methodology}

Perhaps one of the most revolutionary methodology in the arts of the last century was proposed by Marcel Duchamp through his "ready mades". His famous Urinal proposes the transformation of the meaning of form by a simple act of repositioning the form in space. Duchamp's groundbreaking Urinal (Figure 5) was literally "quoted" by Le Corbusier in the small side chapel of Ronchamp, as the repositioning in space of this object allows it to become pure space, under light and shaped by shadows, thus ready and able to accept any new meaning one wishes it to have. The absolutely unique Italian architect Carlo Scarpa, a good friend of Marcel Duchamp, has used systematically the "ready mades" approach especially in the latter part of his own career. In Scarpa's solution for one water spout at the chapel at the chapel of Brion Cemetery of San Vito in Altivole, the "correct" design is repositioned in space by being installed intentionally up-side-down (Figure 6). The water spout is not simply a functional solution masterfully executed, but becomes the idea of a water spout. The "correct" solution has been installed upside-down. The function here is underlined by the negation of function.

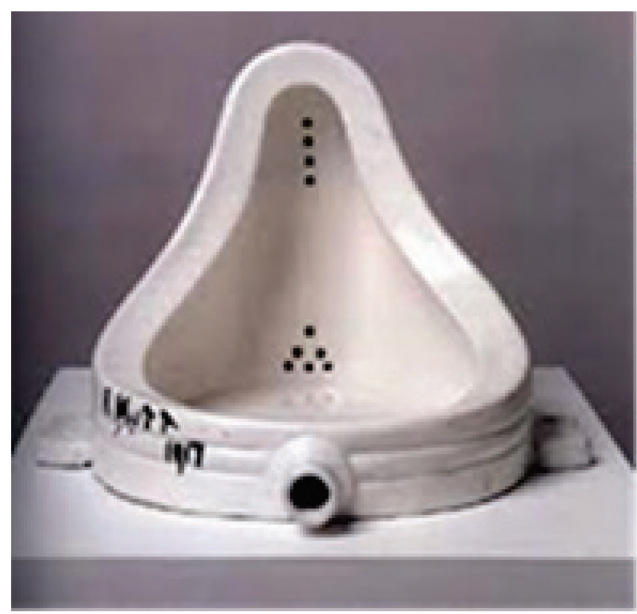

Figure 5. Marcel Duchamp, Urinal Fountain, 1917.
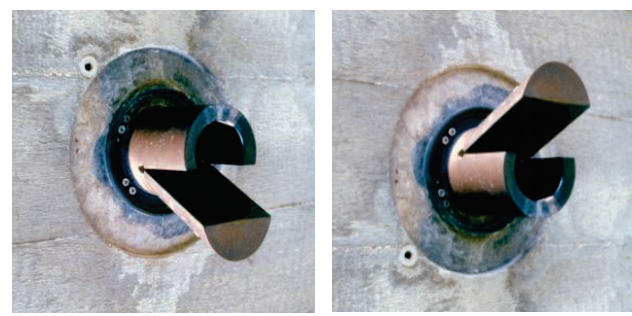

Figure 6. Carlo Scarpa, Detail of water spout in the Brion Vega Cemetery, San Vito in Altivole, Italy, (1968-1978). The "correct" and the "as built" solutions.

Like in Brancusi's work, a table becomes the idea of a table. Like for Corbusier, the column becomes the idea of a column. In all such cases, the artfulness consists in taking the visual image, poignant as it may be, and attempting to transform it into a mental image. Solutions are "found" in reality through a relentless search for 
repeated de contextualizing and recontextualizing that which already exists, bringing about a fresh invented perception which is seen by others as innovation. One intentionally plays here on the Italian words innovazione vs. invenzione. It is not an accident that Bunelleschi spoke of his Opera del Duomo's machine as miraculous inventions.

\section{Translations: Architecture / Literature}

What makes for an act of translation to fail? What makes for an act of translation to succeed? In architecture, the act of translation involves moving from one discipline to another, from one physical context to another, and from one functional program to another. In literature, translation moves a text from one language to another, and like in any other discipline, one is bound to fail if translating words and original syntax, or attempt to translate sound and breathing. Literalness, under the pretext of a misplaced and naïve notion of "respect" for the original, fails to capture meaning. If one attempts to understand the mechanism of how the original text is able to produce a mental image, and find the equivalent mechanism in another language, all poetry becomes possible to translate. In literature, like in architecture, one must translate relationships and not mere facts. One needs to capture the meaning of the space inbetween, the void, and not only the solids that make the void possible. Like for Carlo Scarpa, to graft Zen culture onto Italian Renaissance, both found objects" and ready mades", and then become obsessed with the void in-between, leads to originality. To paraphrase the English poet William Blake, the role of art (and by this one means also mathematics, pure physics, and precise sciences in general) is to scratch the surface of reality to reveal truth.

There are no problems of translation. There are only poor translators.

\section{References}

1) Livio Dimitriu, Stairwells, Pamphlet Architecture vol. 3 (USA Books, New York, 1980).

2) Livio Dimitriu and others, Pamphlet Architecture 1-10 (Princeton University Press, 1980)

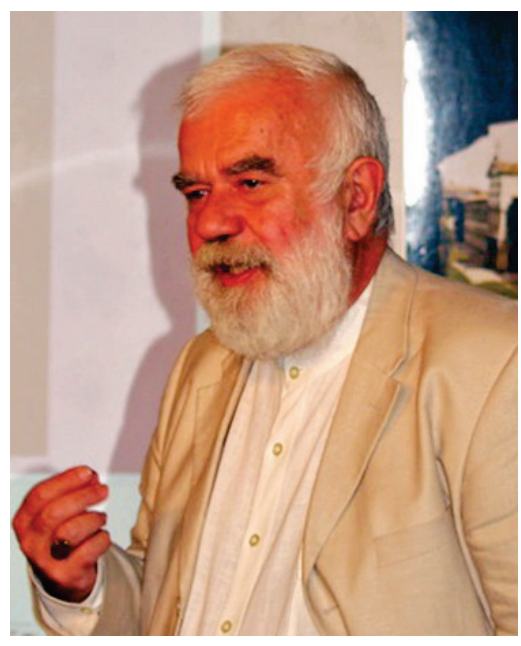

\section{Biographical Sketch:}

Dr. Livio Dimitriu is an American architect/educator, with a New York private practice since 1978. His urban projects have received 13 national and international gold, silver, and bronze medals, and honorable mentions, in the USA, Italy, and Singapore. His projects have been exhibited at the German Architecture Museum, Taiwan Fine Arts Museum, Museum of Finnish Architecture, the Venice Biennale, MoMA, the Smithsonian, Museum of Modern Art/Paris, and many other institutions and galleries in 28 countries. Mr. Dimitriu has authored and contributed to 31 volumes in 10 countries on 3 continents, along with articles and projects in over 100 magazines worldwide.

Mr. Dimitriu founded USA Institute in 1978, a New York public service and research organization sponsored by the banking and marble, granite, and stone industy, academic institutions, and private donors. He is Chief Editor of USA Books, and has been a Senior 
International Magazine Editor for a cummulative 25 years with Controspazio, Octogon, and Arhitext. Mr. Dimitriu co-founded the avant-garde Pamphlet Architecture in 1978, and started the first series of volumes ever on New York Architects in 1987. He has been a founding member of the Islandic School of Architecture, a past member of the Olivetti Foundation Scientific Committee and the Canadian Schools of Architecture Accreditation Board, a Senior Fulbright Scholar to Europe, a grant recipient of the National Foundation for the Arts, and twice a recipient of a Romanian Government Research Grant, and of a Pratt Institute Research Grant.

Mr. Dimitriu has held academic appointments/directorships at 21 universities in North America, Europe, and Asia. He has presided and/or participated in scores of competition juries in Europe, Asia, South America, and the USA, and curated over 45 premiere traveling exhibitions, including New York Architects, Scarpa, Sartoris, Figini \& Pollini, Botta, Gregotti, Vacchini, Purini, and Anselmi.

Mr. Dimitriu accepted a Ph.D. in Theory/History of Architecture with the highest honors from the Ion Mincu University of Architecture and Urbanism in Bucharest, an Honorary Master Architect in Stone from the Antica Corporazione in Verona/Italy, and a B. Arch. from The Cooper Union in New York. He is currently a tenured Full Professor at Pratt Institute.

His early interest in literature received a Romanian National Youth Award for Prose in 1968, after mastering the language during 10 years of forced residence in that country, imposed on a foreign citizen, during late 1950s to late 1960s. In the USA, he audited New York University courses with Alain Robbe-Grillet, Tristan Todorov, Julia Kristeva, and Borelli, and lectured on European avant-garde literature with the Kiremidjian courses at Brooklyn College, Modern Languages Association, and American Society of Esthetics, and other American academic institutions. 